\title{
The effects of Watsu therapy on autonomic cardiovascular modulation and flexibility of children with cerebral palsy
}

\author{
Ertan Tufekcioglu \\ Physical Education Department, \\ King Fahd University of Petroleum and Minerals College of Sciences, \\ Dhahran, Saudi Arabia
}

\section{abstract}

Background: We aimed to compare and examine the effect of aquatic interventions, Watsu ${ }^{\circledR}$ vs Immersion, on the autonomic nervous system and the range of motion in children with cerebral palsy, due to common belief that use of Watsu is beneficial for the special needs.

Material and methods: Twenty-three children (age 7.5 \pm 2.8 ) were randomized to receive Watsu ${ }^{\circledR}$ therapy and Immersion interventions in the cross-over, age-stratified study. Each therapy session lasted 30 minutes twice a week for a total of 10 weeks in two non-consecutive periods. Short-term heart rate variability parameters by using a Polar $\mathrm{H} 7$ heart rate sensor with a signal processing software and the passive range of motion by using a universal goniometer was measured at baseline and post-treatment.

Results: Watsu ${ }^{\circledR}$ therapy significantly improved the heart rate variability parameter $(\mathrm{pNN50,t}=2.312, \mathrm{p}=0.031$ ) and lower flexibility $(t=6.012, p=0.000)$ in comparison to immersion.

Conclusions: In comparison to immersion, Watsu ${ }^{\circledR}$ therapy was shown to be safe and effective for the autonomic modulation and flexibility of children with cerebral palsy. Therefore, it is recommended as a complementary tool for physical therapy on land.

Key words: cerebral palsy, heart rate variability, flexibility, Watsu.

\section{article details}

Article statistics: Word count: 3,660; Tables: 7; Figures: 4; References: 55

Received: May 2020; Accepted: September 2020; Published: December 2020

Full-text PDF: http://www.balticsportscience.com

Copyright @ Gdansk University of Physical Education and Sport, Poland

Indexation: Celdes, Clarivate Analytics Emerging Sources Citation Index (ESCI), CNKI Scholar (China National Knowledge Infrastructure), CNPIEC, De Gruyter - IBR (International Bibliography of Reviews of Scholarly Literature in the Humanities and Social Sciences), De Gruyter - IBZ (International Bibliography of Periodical Literature in the Humanities and Social Sciences), DOAJ, EBSCO - Central \& Eastern European Academic Source, EBSCO - SPORTDiscus, EBSCO Discovery Service, Google Scholar, Index Copernicus, J-Gate, Naviga (Softweco, Primo Central (ExLibris), ProQuest - Family Health, ProQuest - Health \& Medical Complete, ProQuest - Illustrata: Health Sciences, ProQuest - Nursing \& Allied Health Source, Summon (Serials Solutions/ProQuest, TDOne (TDNet), Ulrich's Periodicals Directory/ulrichsweb, WorldCat (OCLC)

Funding: Author gratefully acknowledges the support provided by Deanship of Scientific Research at King Fahd University of Petroleum \& Minerals through Project IN 151004 for this research.

Conflict of interests: Author has declared that no competing interest exists.

Corresponding author: Dr. Ertan Tufekcioglu, King Fahd University of Petroleum and Minerals, College of General Studies - Physical Education; KFUPM, Dhahran, 31261; Saudi Arabia, e-mail: ertan.tufekcioglu@kfupm.edu.sa, suda.sifa@gmail.com

Open Access License: This is an open access article distributed under the terms of the Creative Commons Attribution-Non-Commercial-NoDerivatives 4.0 International (https://creativecommons.org/licenses/by-nc-nd/4.0/), which permits use, distribution and reproduction in any medium, provided the original work is properly cited, the use is non-commercial and is otherwise in compliance with the license. 


\section{INTRODUCTION}

Cerebral palsy (CP) is considered a static encephalopathy in which the primary lesion is non-progressive. $\mathrm{CP}$ is the most common physical disability, as 1 in 323 children has been identified with CP [1].

The growth, plasticity, development, and maturation of the central nervous system can change the clinical presentation, such as movement limitation and impairment of postural control resulting from damage to the immature brain over time [2]. Motor dysfunction and neuromuscular disorders following the neurological deficit and the autonomic nervous system (ANS) imbalance in CP cause disturbance in a homeostatic state, a decrease in the adaptive capacity of the cardiac regulation, and other concomitant chronic disorders [2]. Motor incapacity in $\mathrm{CP}$ is a progressive disorder. However, early diagnosis and treatment can improve its condition $[3,4]$.

ANS activity is amenable to interventions in CP, and the ANS modulation can be observed using non-invasive heart rate variability (HRV) analysis [5,6]. HRV, neural regulation of the heart is the variation of beat-to-beat R-R intervals and the quantitative markers of ANS modulation in milliseconds recorded by an electrocardiogram [5]. HRV is considered for clinical evaluation and to assess the effect of non-pharmacological therapeutic interventions [7], in detecting and following disease processes [8] and as an index activity of the neurophysiological pathway [9]. Assessing HRV that indexes neuro-cardiac functioning can improve our understanding of ANS to interventions in CP [10]. Additionally, it was shown that HRV is linked to autonomic maturation and neurodevelopment [4].

Reliable HRV recording necessitates finical consideration of methodological factors including the study protocol (recording time of day; waking status, sample characteristics (explicit exclusion criteria; the proportion of male participants), ECG signal acquisition and pre-processing settings (i.e., prerecording acclimatization period, recording posture, sampling rate, filtering algorithm) and HRV rational decisions (analyzed recording duration, epoch lengths).

The holistic and somatic therapies can stimulate the vagal nerve and reduce stress hormones alleviating several pediatric conditions, including cerebral palsy [11]. The body has the potential to influence the mind via the bidirectional pathway between the brain and body for psycho-somatic and emotional healing [12].

There is empirical evidence in favor of water (aquatic) therapies for a variety of physical and psychological disorders [13]. In rehabilitation, reduced gravitational forces create a very therapeutic condition for increased mobility. On land, the range of motion (ROM) is targeted using passive stretches provided by a therapist (manual) and sustained stretches in which the patient is placed in a position (positional) for extended periods $[14,15]$.

Active aerobic aquatic exercise intervention studies dominate the literature [3, 20]. Passive Watsu is the only method combining a series of flowing movements, stretches, and manipulations and the least investigated complementary tool in multimodal aquatic treatment settings [16]. The combination of specific techniques and the feeling of trust in warm water can influence emotional state [17], relaxation and autonomic cardiac regulation [18]. Moderate pressure touch and therapeutic properties of warm water might double the expected effects due to potential emotional contagion [19].

For high-quality design studies, standardized protocols with adequate sample sizes, scope, and good reports about the testing procedure are needed [16, 20, 21]. On this subject, our general aim is to contribute to evidence-based rehabilitation in CP. Mainly, the aim is 
to examine and compare the effect of passive Watsu therapy and immersion protocols on HRV and ROM parameters in children with CP.

\section{MATERIAL AND METHODS}

The single-blinded randomized and age-stratified crossover study took place in two nongovernmental rehabilitation complexes providing treatment and therapeutic work on land and in water to the patient with a variety of physical disorders.

\section{SUBJECTS}

Twenty-three children ( $\mathrm{n}=23$, age $7.52 \pm 2.78$, BMI $19.04 \pm 1.62$ ), more than power analysis of $\mathrm{G}^{*}$ Power recommendation (\#15), participated in the study. They were diagnosed with clinical mild/moderate spastic CP (International Classification of Diseases and Related Health Problems 10th, ICD-10), of either gender, showing the absence of seizures for the past 30 days with no medical history of ANS effecting diseases participated in this study. They were able to understand basic verbal commands and report sensitivity to pain. All test procedures and arrangements were explained to the parents or caretakers, who then signed the informed consent document approved by the Deanship of Scientific Research. Significance ( $p>0.05$ ) were not seen in the physical characteristic of the groups (Table 1).

Table 1. Physical characteristics of the groups. Mean (SD)

\begin{tabular}{|c|c|c|c|c|c|}
\hline \multicolumn{2}{|c|}{ Group } & Age (years) & Weight $(\mathrm{kg})$ & Height (m) & BMI $\left(\mathrm{kg} / \mathrm{m}^{2}\right)$ \\
\hline \multirow{2}{*}{ WI $(n=12)$} & Mean & 7.92 & 17.92 & 0.97 & 18.99 \\
\hline & Std. & 3.12 & 4.56 & 0.13 & 1.77 \\
\hline \multirow{2}{*}{ IW $(n=11)$} & Mean & 7.09 & 16.61 & 0.93 & 19.09 \\
\hline & Std. & 2.43 & 3.44 & 0.10 & 1.53 \\
\hline \multirow{2}{*}{ Total $(\mathrm{N}=23)$} & Mean & 7.52 & 17.29 & 94.83 & 19.04 \\
\hline & Std. & 2.78 & 4.03 & 11.26 & 1.62 \\
\hline
\end{tabular}

The portion of the participants in level II was $52.2 \%$, whereas of the participants in level I $-48.8 \%$, based on the gross motor function classification system (GMFCS). Regarding topographic distribution, $7.7 \%$ had diplegia, and $92.3 \%$ had hemiplegia (Table 2).

Table 2. The participants' GMFCS levels and topographic distribution

\begin{tabular}{|c|c|c|c|c|c|c|c|c|}
\hline \multirow{2}{*}{ Group } & \multirow{2}{*}{$\mathrm{n}$} & \multicolumn{2}{|c|}{ Gender } & \multirow{2}{*}{ Age } & \multicolumn{2}{|c|}{ Limb distribution } & \multicolumn{2}{|c|}{ GMFCS } \\
\hline & & $\mathrm{F}$ & M & & Diplegia & Hemiplegia & 1 & II \\
\hline WI & 12 & 7 & 5 & $\begin{array}{c}7.92 \\
(3.11)\end{array}$ & 1 & 11 & 6 & 6 \\
\hline IW & 11 & 4 & 7 & $\begin{array}{c}7.09 \\
(2.42)\end{array}$ & 1 & 10 & 5 & 6 \\
\hline
\end{tabular}

\section{EXPERIMENTAL DESIGN}

Participants were assigned randomly to either Watsu (WI) or Immersion first (IW) groups based on their arrival time to the facility. The allocation was concealed from the assessors and the therapists. Each participant serves as his/her control in estimating the treatment effect. The study consisted of a 6-week washout interval during which no therapy was applied (Fig. 1). Each therapy session lasted 30 minutes, twice a week, during the two 10-week experimental phases. 


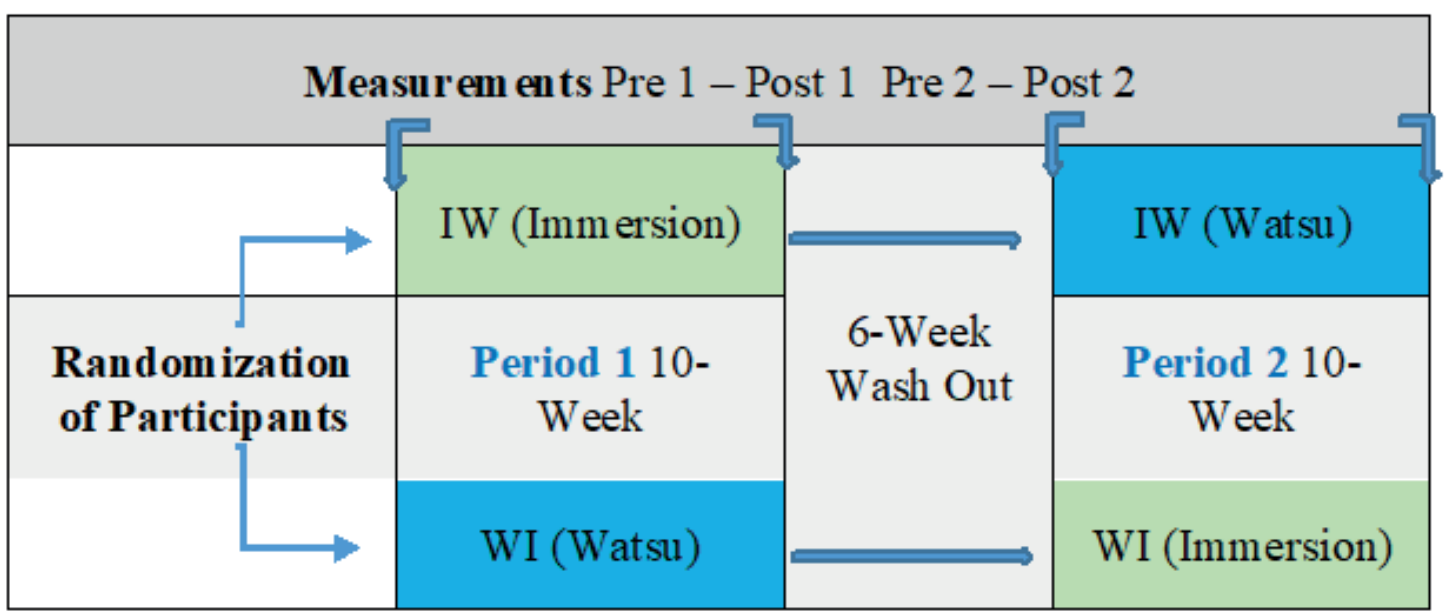

Fig. 1. The crossover design of the study.

Participants' food intake and life routine were maintained during the 24 hours preceding the test. After ensuring the same conditions, the tests were performed between 8:00 am, and 10:00 am in still lying supine in a quiet room with low light and optimal temperature $\left(27^{\circ} \mathrm{C} \pm 1.3\right)$. The strap was fitted around the chest of each participant. Next, the heart rate sensor was fitted on the strap and located in the middle area below the nipples. The participants maintained the average respiratory rate of 16.7 (SD: 1.94) in recordings. ECG signal was transmitted by Polar H7 Bluetooth Heart Rate Sensor \& Fitness Tracker (Polar Electro Oy, Kempele, Finland) on the strap and received by IOS device (Apple Inc., CA, USA) with a digital standardized HRV+ signal processing software that fully supports Bluetooth (4.0) Smart connectivity.

The corresponding data files were then transmitted to a personal computer as text files. After artefact correction (medium level filter) by Kubios HRV 2.2., (a software analyzing biosignals), HRV parameters (Table 3) were obtained for statistical analyses.

Table 3. HRV time and frequency domain parameters obtained in the study

\begin{tabular}{ll} 
Mean R-R & All intervals between adjacent QRS complexes also defined as interbeat intervals \\
\hline RMSSD & The square root of the mean of the squares of the successive differences between adjacent R-R \\
\hline pNN50 & The proportion of NN50 divided by the total number of NNs \\
\hline LF & $0.04-0.15 \mathrm{~Hz}$ representing both SNS and PNS tone by baroreflex activity. \\
\hline HF & $0.15-0.40 \mathrm{~Hz}$ representing PNS tone and fluctuations caused by respiratory sinus arrhythmia \\
\hline
\end{tabular}

The standard spectral analysis was applied to the 5-minute lying supine HRV recordings. The 5-minute recording is the main data tool for the literature on HRV correlating with $24 \mathrm{~h} \mathrm{HRV}$ recording [21]. 5 min recordings length is suggested for reliable HRV indices to evaluate physiological changes [22]. Another study [23] concluded that clinical and optimal performance progress induced by the interventions could be assessed using shortterm HRV indices when clients breathe at regular rates ( 11-20 bpm). A Meta-Analysis on psychometric properties of HRV revealed that HRV is a reliable measure of autonomic respond and modulation in the pediatric sample [23]. Polar H7 heart rate monitor is confirmed to be valid [24] and reliable in resting and in mild activities [25].

ROM was measured using a standard universal larger plastic goniometer (121/4 inches) by physical therapists. High intertester reliability and validity for goniometric measurements were reported [27, 28, 29]. The goniometer measurements are used for the longitudinal 
monitoring of hip function [30]. The pelvis was stabilized through manual fixation to prevent rotation with knees in a neutral position, avoiding the rotation in the hip to standardize procedures. Hip and knee were in neutral rotation, avoiding limitation by tight rectus femoris muscle for measuring knee flexion (Table 4). Full end-point measurements were made to the nearest $1^{\circ}$.

Table 4. Procedure of ROM measurements and the use of a goniometer

\begin{tabular}{|c|c|c|c|c|c|}
\hline \multicolumn{2}{|c|}{ Passive ROM } & Body position & Goniometer axis & $\begin{array}{l}\text { G. stationary arm } \\
\text { aligned with }\end{array}$ & $\begin{array}{l}\text { G. moving arm } \\
\text { aligned with }\end{array}$ \\
\hline \multirow{2}{*}{ Shoulder } & Extension & Prone & \multirow{2}{*}{$\begin{array}{l}\text { Center of the } \\
\text { humeral head }\end{array}$} & \multirow{2}{*}{$\begin{array}{l}\text { Thorax mid- } \\
\text { axillary line }\end{array}$} & \multirow{2}{*}{ Humerus } \\
\hline & & & & & \\
\hline Elbow & Flexion & Supine & $\begin{array}{l}\text { Elbow lateral } \\
\text { epicondyle }\end{array}$ & Humerus & Radius \\
\hline Knee & & & $\begin{array}{l}\text { Lateral femoral } \\
\text { epicondyle }\end{array}$ & Femur & Fibula \\
\hline \multirow{2}{*}{ Hip } & & & \multirow{2}{*}{$\begin{array}{c}\text { Femoral greater } \\
\text { trochanter }\end{array}$} & \multirow{2}{*}{$\begin{array}{l}\text { Trunk mid- } \\
\text { axillary line }\end{array}$} & \multirow{2}{*}{ Femur } \\
\hline & Extension & Side-lying & & & \\
\hline
\end{tabular}

\section{EXCLUSION CRITERIA}

Participants with surgery for saliva control and taking drugs affecting autonomic cardiac function and saliva secretion in the last 15 days before the study, previous history of cardiac disease were not involved in the study. Participants with pathologies associated with infectious or viral states, or the inability to maintain an orthostatic position were not included. Participants were excluded after their second absences.

Participants that fulfilled initial inclusion criteria were subsequently excluded for the following reasons: The participants (\#5) who reported later than the measurements were excluded. Participants with observed fatigue (\#3), and the second absence in the intervention period (\#3) were excluded (Fig. 2). No other adverse effect was observed.

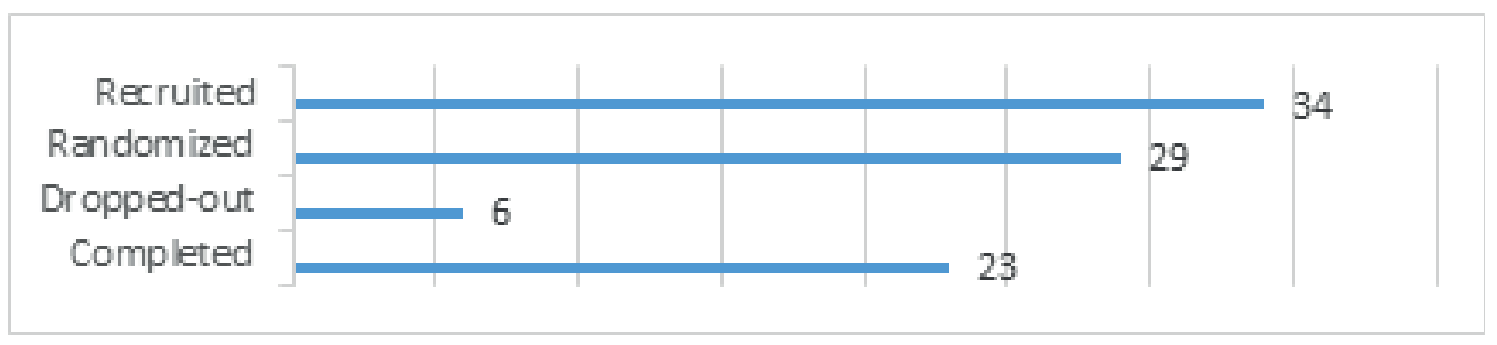

Fig. 2. The numbers of excluded participants during the study

\section{INTERVENTION PROTOCOL}

The day after the tests, two certified Watsu therapists with more than five years of experience in treating and evaluating children with CP have applied the adapted Watsu to the participants. The typical Watsu session involved stretches and trunk rotational and rocking movements, in flexion, extension, traction and rotation with no open sandwich techniques. However, the restrictions of each individual were considered for a safe and enjoyable session.

Constant support at the back of the participant's head and neck to avoid submersion was maintained by specifically manufactured floating equipment during immersion. During 
this floatation session, the rest of the participant's body was kept horizontally in the water. The water and air temperature were $34^{\circ} \mathrm{C}$ and $31^{\circ} \mathrm{C}$, respectively. The post-test was performed the day after the last sessions of both periods.

\section{Data analysis}

The carryover effect was analyzed by the calculation of the sum of the measured values in both periods. The comparison was made with an independent sample t-test. In the case of significant results, no comparison was performed between the differences of both therapies. The effect of both therapies was analyzed based on 1st-period values. When no carryover effect was seen, the effectiveness of both therapies was evaluated based on the difference between the results of the two therapies. The independent sample t-test was used for this purpose. The significance level for all tests was $5 \%(p<0.05)$.

\section{RESULTS}

HRV values did not show carryover effect (Mean R-R t(21) $=0.143, p=0.888$; RMSSD $\mathrm{t}(21)=0.987, \mathrm{p}=0.335$; pNN50 $\mathrm{t}(21)=-0.068, \mathrm{p}=0.947), \mathrm{HF}(\mathrm{t}=-0.224, \mathrm{p}=0.825)$, and $\mathrm{LF},(\mathrm{t}=-0.768, \mathrm{p}=0.451)$. Mean $\mathrm{R}-\mathrm{R}$ and RMSSD improved insignificantly compared to Immersion $(\mathrm{t}(21)=1.084, \mathrm{p}=0.291) ; 95 \%$ CI $(-22.67,72.02) ;(\mathrm{t}(21)=1.552, \mathrm{p}=0.136)$, respectively (Table 5).

Table 5. Changes in all time-domain HRV indices of the groups. Mean (SD)

\begin{tabular}{cccccc} 
Groups & HRV Time & \multicolumn{2}{c}{ Period 1 } & \multicolumn{2}{c}{ Period 2 } \\
\hline WI & \multirow{2}{*}{ Mean R-R (ms) } & $504.83(52.63)$ & $558.67(90.66)$ & $518.42(55.21)$ & $547.67(59.04)$ \\
IW & $513.91(43.69)$ & $552.91(46.33)$ & $526.73(42.69)$ & $565.82(45.71)$ \\
\hline WI & \multirow{2}{*}{ RMSSD (ms) } & $18.00(9.55)$ & $30.17(16.25)$ & $24.25(15.07)$ & $33.50(17.29)$ \\
IW & & $28.27(12.39)$ & $33.36(12.71)$ & $27.36(12.46)$ & $37.27(15.28)$ \\
WI & \multirow{2}{*}{ pNN50 } & \multirow{2}{*}{$3.08(5.02)$} & $11.25(14.39)^{*}$ & $8.08(9.05)$ & $13.33(12.10)$ \\
IW & & & $13.64(8.69)$ & $9.45(8.74)$ & $19.09(13.08) *$ \\
\hline
\end{tabular}

Watsu improved pNN50 significantly $(t=2.312, p=0.031), 95 \%$ CI $(0.84,15.90)$, (Fig. 3).

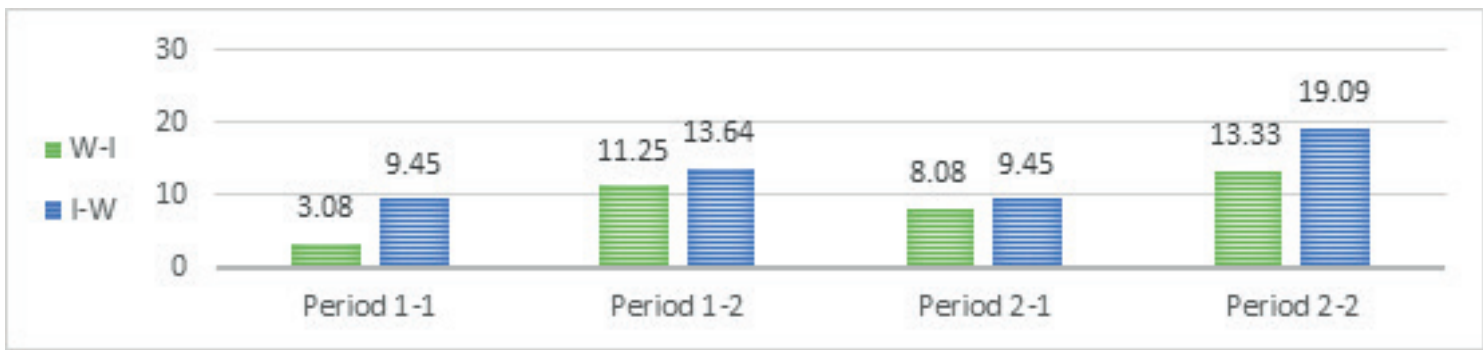

Fig. 3. The pNN50 changes of the groups

Improvements in HF and LF were not significant ( $(\mathrm{t}=1.492, \mathrm{p}=0.151) 95 \% \mathrm{CI}(-2.09,12.72)$, $(\mathrm{t}=-0.811, \mathrm{p}=0.426) 95 \% \mathrm{CI}(-22.81,10.01$, respectively) ) compared to immersion (Table 6). 
Table 6. The participants' HRV frequency domain indices. Mean (SD)

\begin{tabular}{cccccc} 
Group & HRV Frequency & \multicolumn{2}{c}{ Period 1 } & \multicolumn{2}{c}{ Period 2 } \\
\hline WI & \multirow{2}{*}{ HF (nu) } & $13.12(6.88)$ & $19.40(11.03)$ & $19.83(9.41)$ & $23.78(9.42)$ \\
IW & & $16.43(8.13)$ & $20.59(9.04)$ & $16.23(8.74)$ & $23.38(7.50)$ \\
\hline WI & \multirow{2}{*}{ LF (nu) } & $69.68(15.01)$ & $76.63(15.73)$ & $73.03(21.35)$ & $78.95(13.97)$ \\
IW & & $57.44(6.60)$ & $70.95(15.31)$ & $62.23(11.10)$ & $68.30(12.94)$ \\
\hline
\end{tabular}

The upper flexibility difference between the two therapies was not significant $(t=0.804$, $\mathrm{p}=0.431) 95 \%$ CI $(-1.26,2.84)$. Relevant carryover effects were observed in upper flexibility $(t=-2.580, p=0.017)$. No evidence of relevant carryover effects was observed in lower flexibility $(t=-1.498, p=0.149)$, (Table 7 ).

Table 7. The participants' range of motion (ROM) results. Mean (SD)

\begin{tabular}{cccccc} 
Group & ROM & \multicolumn{2}{c}{ Period 1 } & \multicolumn{2}{c}{ Period 2 } \\
\hline WI & \multirow{2}{*}{ Upper } & $118.42(9.90)$ & $121.23(7.17)$ & $118.74(9.39)$ & $119.15(8.74)$ \\
IW & & $93.18(20.04)$ & $95.20(19.43)$ & $93.53(19.52)$ & $98.63(19.00)$ \\
\hline WI & \multirow{2}{*}{ Lowe } & $82.07(22.55)$ & $86.10(22.28) *$ & $82.35(22.39)$ & $84.02(21.83)$ \\
IW & & $81.13(10.53)$ & $83.48(10.18)$ & $81.13(10.53)$ & $86.81(10.23) *$ \\
\hline
\end{tabular}

Watsu significantly improved lower ROM compared to Immersion $(\mathrm{t}=6.012, \mathrm{p}=0.000)$ 95\% CI (3.72, 7.65), (Fig. 4).

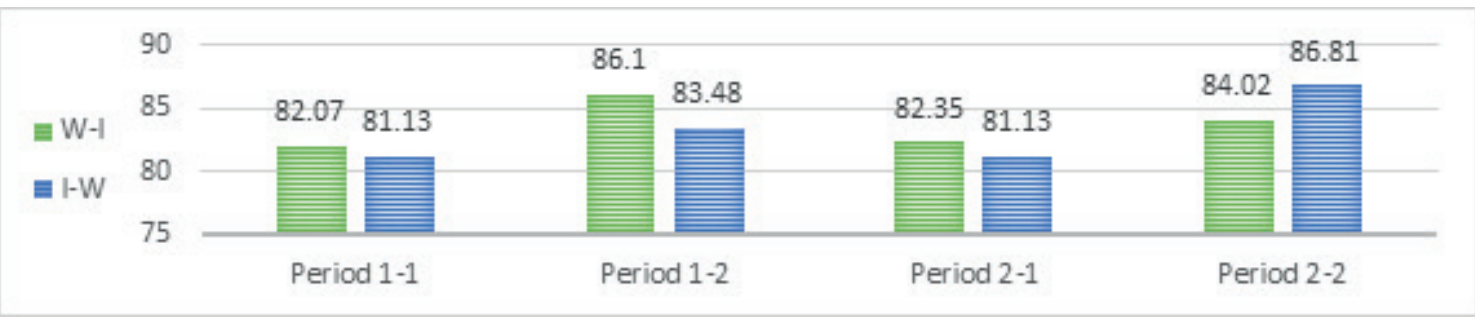

Fig. 4. The lower ROM changes of the groups

\section{DISCUSSION}

This first study in the literature comparing the effect of passive Watsu therapy and immersion has revealed significant results. Although selected HRV measures showed a positive trend after both therapies, the overall result favors the use of Watsu therapy in CP.

There are a few studies with encouraging findings in the literature. However, these studies show variety in their population and selected parameters. To date, no study investigated the HRV and ROM of children who are 4-12 years old. The variables of the studies included pain in fibromyalgia patients [31], functional capacity, anxiety and depression in patients with Parkinson disease [32], functional health status and ROM of children with juvenile idiopathic arthritis [33], physical function, pregnancy, and other physiological parameters of healthy individuals [34]. The positive findings on locomotor cardiac synchronization of obese young males [35] and the ROM of active young swimmers [36] were also noted.

A Watsu therapist provides constant tactile, kinesthetic input when working on limbs one by one, due to stretching muscles, changing joint position, tendon tension, rocking and gently massaging. Being floated, touched, stretched, gently rocked, pulled and 
pushed into positions elicit a variety of external inputs sent to the sensory cortex that can synchronize with internal afferent inputs and rhythm. The cerebellar-motor cortex interactions throughout the Watsu sessions can form a base for psychomotor functioning and development.

This kind of sensory reintegration in Watsu is likely to enhance nervous system functions and help filter out unnecessary information, tolerate and control responses to challenging signals, which can improve emotional wellbeing [37, 38]. The characteristic of being cradled in the nurturing arm of a therapist in warm water can provide signals of trust in high levels and concomitant positive emotions [34]. However, it is worth considering the individualized proprioceptive sensory diet using the advanced and adapted skills for the over-aroused or under aroused children. Thus, the change in the rhythm of the bodily systems, including the cardiac system alters the state of consciousness - these afferent inputs sent to the medulla and cortex $[39,40]$. Thus, ANS can modulate the physiological and emotional response in a timely and proper manner indicated by higher HRV [41] correlating with positive emotions [42]. Higher levels of resting vagally-mediated HRV are linked to the performance of executive functions like attention and emotional processing by the prefrontal cortex [21]

All sensory information from the heart from proprioceptors, chemoreceptors, and mechanoreceptors and information from the cerebral cortex and limbic system is integrated with the cardiovascular center of the medulla of the brainstem for the cardiovascular modulation [43]. Thus, the sensorial inputs in different body positions might influence better autonomic cardiac modulation, higher pNN50 indices of HRV [42]. Moderate touch (tactile input) dominates the entire Watsu session, especially the techniques called "shoulder rotation" and "sandwich". The gentle stroking in the shoulder and neck area might have stimulated the pressure receptors and vagal nervous [44]. This gentle stroking conveys a pleasant sensation via touch-sensitive C-tactile nerve fibers when activated in Watsu [45]. It is known that tactile receptors transmit the sensory stimulus to the brain, causing a faster reaction than other types of the stimulus [46]. In addition to that, $\mathrm{C}$ tactile fibers transform the sensory stimulation into the pleasurable sensations and emotional quality of tactile input. Although the Watsu dimension of tactile information can address psychological traumas and enhance wellbeing, potential over-arousal state of a person with traumatic experience should be considered [34]. It can boost the desired outcomes and help alleviate touch deprivation symptoms [45]. However, the effect of warm water as a whole-body stimulator for sensory reintegration, body awareness and neuromuscular re-education still needs to be investigated in future studies [34].

Another positive change due to gentle stroking and massage is the reduced cortisol levels and increased serotonin and oxytocin, which plays a role in social bonding $[47,10]$. Thus, socio-emotional development in early childhood and later in life is supported [11, 18, 48]. These possible biochemical changes may bring additional benefits to the therapeutic table, including the release of pain and strengthened immune function and contribute to better accordance between autonomic, emotional, and physical flexibility $[8,49]$.

Understanding the role that the intrinsic cardiac nervous system plays in cardio-vascular modulation is crucial [50]. Mechanical and hormonal changes are transformed into neurological inputs by sensory neurons in the myocardium. These sensory inputs are sent to the brain via afferent pathways contributing to heart-brain interactions. The role of heart in the altered rates, rhythms, and patterns of afferent traffic, resettlement ] of cortical functioning can trigger emotional restructuring [39]. Such emotional selfregulation can be reflected in higher pNN50 after Watsu. Another type of touch called "intentional touch" is used to avoid overstimulation of fear of intimacy and closeness in 
Watsu. The number of intentional touch techniques can be regulated to maintain pleasant and refreshed feelings.

The current study showed that the clinical pediatric goal of improved lower ROM could be achieved after Watsu therapy. The specific gentle stretching in warm water is the possible factors increasing lower ROM [36] via muscle relaxation and pain relief [51, 52, 53]. A study indicated a ROM increase after Watsu therapy in children with juvenile idiopathic arthritis and improved functional health status with an insignificant improvement in the participants' ROM in comparison to traditional hydrotherapy [33]. It is important to note that passive movements and stretching in Watsu may elicit additional benefits in comparison to active aquatic therapies for the relief of joint problems. Another study indicated the significant lower ROM changes after single Watsu session among active young swimmers [36].

An experienced Watsu therapist uses stretching, rocking and cradling movements, mobilization of joints and soft tissues with his/her own hands, arms, legs, and even body [17]. Unlike manual and positional stretching on land, reduced gravitational forces in water can alleviate muscular tonus, joint stiffness and pain to further levels [52]. The thermal effects of warm water (33-35 degrees Celsius) decrease gamma fiber activity, spasticity [53] and enhance the condition of the overused and painful muscles elasticity and joints due to neuro-motor impairments [52]. Improved balance and coordination enhance flexibility. Even though low-level coordination improvements are possible using single limb techniques of Watsu [53], we recommend integrating Watsu with programs such as hippotherapy to improve flexibility via balance and coordination.

Although the adaptation of ANS, cardiac hyporesponsivity and clinical outcomes to immersion still needs to be investigated, the insignificant positive changes in the current study support the use of head-out water immersion. Immersion enhances autonomic outflow and cardiovagal baroreflex sensitivity [54, 55], thus HRV. The mechanical therapeutic effect of buoyancy, hydrostatic pressure and viscosity in immersion might have contributed to the traditional hydrotherapy benefits and ROM [33].

The constant close support of the upper body to keep the head above the surface and spinal column aligned might have limited the upper limbs mobilization. Designing Watsu sessions that address certain factors such as limitations in upper ROM may provide better health outcomes. Therefore, the goal specific adjustability of Watsu sessions depends on the large repertoire of the highly trained therapist may widen the horizons in the clinical settings. Considering the main goal as achieving higher functional independence levels and the increase in lower ROM, Watsu can be a complementary therapy. Moreover, relaxing and preparatory (higher HRV \& ROM) improvements encourage children to achieve higher health and skill-related physical fitness parameters that can enable participation in sports competitions. Although the carry-over effect from the aquatic therapies to performance on land still needs to be clarified, Watsu therapy intervals are suggested in active exercise periods.

In light of the findings, various extrapolations can be made from this first study. Besides, incorporating Watsu in the aquatic therapy programs due to physiological effects, Watsu approach has a potential sense of family affection, enjoyment and motivation that can make it easy to apply in a lifelong rehabilitation process [53].

Considering the limitations of the current study, follow-up measurements and enjoyment assessment of the children were not performed. In addition, synchronized multiple physiological recordings were not used. 


\section{CONCLUSIONS}

The clinical importance of this unique study is that the use of Watsu passive therapy is found applicable for the first time in autonomic modulation and ROM of the children with CP.

Thus, enhanced modulation of ANS can alleviate the symptoms of motor dysfunction due to neuromuscular disorder and increase the adaptive capacity of the cardiac regulation leading to stress and tension release in the muscles and joints. These effects can enhance overall wellbeing.

These first empirical pieces of evidence can provide new implications in the field of passive aquatic therapy for researchers. The findings are the first to suggest further personalization of rehabilitation programs using tools of Watsu. Future randomized, blinded trials with large sample size with follow up measurements are needed to confirm our results.

\section{REFERENCES}

[1] Christensen D, Van Naarden BK, Doernberg NS, et al. Prevalence of cerebral palsy, co-occurring autism spectrum disorders, and motor functioning - Autism and Developmental Disabilities Monitoring Network, Dev Med Child Neurol. 2014;56(1):59-65. https://doi.org/10.1111/dmcn.12268

[2] Ferreira MC, Pastore C, Imada R, et al. The autonomic nervous system in individuals with cerebral palsy: A controlled study. J Oral Path. Med. 2011;40(7):576-81. https://doi.org/10.1111/j.1600-0714.2011.01008.x

[3] Zwier JN, van Schie PE, Becher JG, Smits DW, Gorter JW, Dallmeijer AJ. Physical activity in young children with cerebral palsy. Disabil Rehabil. 2010; 32(18):1501-8. https://doi.org/10.3109/09638288.2010.497017

[4] Lidija D, Bojko B, Hristina C, et al. Assessment of general movements and heart rate variability in the prediction of neurodevelopmental outcome in preterm infants. Early Human Development. 2016;99:7-12. https://doi.org/10.1016/j. earlhumdev.2016.05.014

[5] Kleiger RE, Stein PK, Bigger JT. Heart Rate Variability: Measurement and Clinical Utility. Annals of Noninvasive Electrocardiology. 2005;10(1):88-101. https://doi.org/10.1111/j.1542-474X.2005.10101.x

[6] Sztajzel J. Heart rate variability: A noninvasive electrocardiographic method to measure the autonomic nervous system. Swiss Med Wkly. 2004. 134(35-36), 514-22.

[7] Catai AM, Pastre CM, Godoy MF, Silva E, Takahashi ACM, Vanderlei LCM. Heart rate variability: Are you using it properly? Standardisation checklist of procedures. Brazilian J Phys Therapy. 2020;24(2):91-102. https://doi. org/10.1016/j.bjpt.2019.02.006

[8] Lischke A, Jacksteit R, Moeller A Pahnke R, Hamm AO, Weippert M. Heart rate variability is associated with psychosocial stress in distinct social domains. J Psychosomatic Res. 2018:106:56-61. https://doi.org/10.1016/j. jpsychores.2018.01.005

[9] Williams DP, Koenig J, Carnevali L, Sgoifo A, Jarczok MN, Sternberg EM, Thayer JF. Heart rate variability and inflammation: A meta-analysis of human studies. Brain, Behavior, and Immunity 2019: (IF 6.170). https://doi. org/10.1016/j.bbi.2019.03.009

[10] Amichai T, Katz-Leurer M. Heart rate variability in children with cerebral palsy: Review of the literature and metaanalysis. NeuroRehabilitation. 2014:35(1):113-122. https://doi.org/10.3233/NRE-141097

[11] Field T. Pediatric massage therapy research: A narrative review. Children. Sp. Issue: Complementary and Integrative Movement Therapies for Children. 2019 6(6), 78; https://doi.org/10.3390/children6060078

[12] Tarsha MS, Park S, Tortora S. Body-centered interventions for psychopathological conditions: A review. Frontiers in Psychology. 2020;10:2907. https://doi.org/10.3389/fpsyg.2019.02907

[13] Kamioka H, Tsutani K, Okuizumi H, et al. Effectiveness of aquatic exercise and balneotherapy: A summary of systematic reviews based on randomized controlled trials of water immersion therapies. J Epidemiol. 2010 20(1):2-12. https:// doi.org/10.2188/jea.JE20090030

[14] Akinola BI, Gbiri CA, Odebiyi DO. Effect of a 10-week aquatic exercise training program on gross motor function in children with spastic cerebral palsy. Global Pediatric Health. 2019 June 25. https://doi.org/10.1177/2333794X19857378

[15] Groppe M, Mattern-Baxter K, Davenport TE. Passive stretching and its effect on spasticity and range of motion in children with cerebral palsy: A systematic review. J Student Phys Therapy Res. 2012: 5(1), Article 2

[16] Choi K, Cho S. The effect of underwater intervention in children with cerebral palsy on the range of motion, coordination and balance: meta-analysis. Korean Journal of Integrated Medicine, 2019:7 (3), $71-83$.

[17] Dull H. Watsu ${ }^{\circledR}$ : Basic and explorer paths. Watsu ${ }^{\circledR}$ Publishing. 4th edition. 2008.

[18] Tufekcioglu E, Cotuk HB. Comparison of heart rate variability in different body position on land and in water. Nigde University J. of Phy. Edu. and Sport Sciences. 2009: 3(3)

[19] Field T. Social touch, CT touch and massage therapy: A narrative review. Developmental Rev. 2019;51:123-145. https://doi.org/10.1016/j.dr.2019.01.002

[20] Gorter JW, Currie SJ. Aquatic exercise programs for children and adolescents with cerebral palsy: What do we know and where do we go? Int J Pediatrics. 2011:712165. https://doi.org/10.1155/2011/712165 
[21] Jorgic B, Dimitrijevic L, Lambeck J, Aleksandrovic M, Okičić T, Madić D. Effects of aquatic programs in children and adolescents with cerebral palsy: Systematic review. Sport Sci. 2012:5(49)-56.

[22] Shaffer F, Ginsberg JP. An Overview of Heart Rate Variability Metrics and Norms. Frontiers in Public Health. 2017:5;258. https://doi.org/10.3389/fpubh.2017.00258

[23] Seppälä S, Laitinen T, Tarvainen MP, et al. Normal values for heart rate variability parameters in children 6-8 years of age: the PANIC Study. Clin Physiol Funct Imaging. 2014;34:290-6.10.1111. https://doi.org/10.1111/cpf.12096

[24] Weiner OM, McGrath JJ. Test-retest reliability of pediatric heart rate variability. A meta-analysis. J Psychophysiol. 2017;31(1):6-28. https://doi.org/10.1027/0269-8803/a000161

[25] Plews DJ, Scott B, Altini M, Wood M, Kilding AE, Laursen PB. Comparison of heart-rate-variability recording with smartphone photoplethysmography, Polar H7 chest strap, and electrocardiography. Int J Sports Physiol Perform. 2017;1;12 (10):1324-1328. https://doi.org/10.1123/ijspp.2016-0668

[26] Georgiou K, Larentzakis AV, Khamis NN, Alsuhaibani GI, Alaska YA, Giallafos EJ. Can wearable devices accurately measure heart rate variability? A systematic review. Folia Medica, 2018;60(1):7-20. https://doi.org/10.2478/folmed-2018-0012

[27] Soucie Jm, Wang C, Forsyth A, et al. Range of motion measurements: reference values and a database for comparison studies. Hemophilia. 2011;17:500-507. https://doi.org/10.1111/j.1365-2516.2010.02399.x

[28] Chapleau J, Canet F, Petit Y, Laflamme GY, Rouleau DM. Validity of goniometric elbow measurements: comparative study with a radiographic method. Clin Orthop Relat Res. 2011;469(11):3134-3140. https://doi.org/10.1007/s11999011-1986-8

[29] Van Rijn SF, Zwerus EL, Koenraadt KL, Jacobs WC, van den Bekerom MP, Eygendaal D. The reliability and validity of goniometric elbow measurements in adults: A systematic review of the literature. Shoulder Elbow. 2018;10(4):274284. https://doi.org/10.1177/1758573218774326

[30] Nussbaumer, S., Leunig, M., Glatthorn, J. F., Stauffacher, S., Gerber, H., \& Maffiuletti, N. A. Validity and test-retest reliability of manual goniometers for measuring passive hip range of motion in femoroacetabular impingement patients. BMC Musculoskeletal Disorders. 2010;11:194. https://doi.org/10.1186/1471-2474-11-194

[31] Zamuner AR, Andrade CP, Arca EA, Avila MA. Impact of water therapy on pain management in patients with fibromyalgia: current perspectives. J Pain Res. 2019;12:1971-2007. https://doi.org/10.2147/JPR.S161494

[32] Ribeiro I, Lima F, Rosa T, et al. The effects of the Watsu method on functional capacity, anxiety and depression in patients with Parkinson disease. Archives in Biosciences \& Health. 2019;1(1):11. https://doi.org/10.18593/abh.19211

[33] Ramírez NP, Cares PN, Peñailillo PSM. Effectiveness of Watsu therapy in patients with juvenile idiopathic arthritis. A parallel, randomized, controlled and single-blind clinical trial. Rev Chil Pediatr. 2019;90(3):283-92.

[34] Schitter AM, Fleckenstein J, Frei P, Taeymans J, Kurpiers N, Radlinger L. Applications, indications, and effects of passive hydrotherapy WATSU (WaterShiatsu)-A systematic review and meta-analysis. PLoS ONE. 2020;15(3). https:// doi.org/10.1371/journal.pone.0229705

[35] Tufekcioglu E, Erzeybek MS, Kaya F, Ozan G. The effect of 12-week passive aquatic bodywork on sympathovagal balance of obese youth. J Educ Train Stud. 2018;6(2):166-76. https://doi.org/10.11114/jets.v6i2.2963

[36] Tufekcioglu E, Hassanain M. Acute effect of single watsu therapy on the flexibility of young male swimmers Conference: European College of Sports Sciences, Vienna; 2016.

[37] Tarsha MS, Park S, Tortora S. Body-Centered interventions for psychopathological conditions: A review. Frontiers in Psychology. 2020;10:2907. https://doi.org/10.3389/fpsyg.2019.02907

[38] Garcia-Rill E, Kezunovic N, Hyde J, Simon C, Beck P, Urbano FJ. Coherence and frequency in the reticular activating system (RAS). Sleep Medicine Reviews. 2013;17(3):227-238. https://doi.org/10.1016/j.smrv.2012.06.002

[39] Elbers J, McCraty R. Heart math approach to self-regulation and psychosocial well-being. J Psychol Africa, 2020;30(1):69-79. https://doi.org/10.1080/14330237.2020.1712797

[40] Maczkowiak SG, Holter G, Otten H. Watsu ${ }^{\circledR}$ - the effect of differently accentuated movement therapy interventions on clinically depressive patients. Bewegungstherapie und Gesundheitssport. 2007;23(2):58-64. https://doi. org/10.1055/s-2007-960607

[41] Choi KH, Kim J, Kwon OS, Kim MJ, Ryu YH, Park JE. Is heart rate variability (HRV) an adequate tool for evaluating human emotions? - A focus on the use of the International Affective Picture System (IAPS) Psychiatr Res. 2017;251: 192-196. https://doi.org/10.1016/j.psychres.2017.02.025

[42] De Witte NAJ, Sütterlin S, Braet C, Mueller SC. Getting to the heart of emotion regulation in youth: The role of interoceptive sensitivity, heart rate variability, and parental psychopathology. PLoS ONE. 2016;11(10). https://doi. org/10.1371/journal.pone.0164615

[43] Shaffer F, McCraty R, Zerr CL. A healthy heart is not a metronome: An integrative review of the heart's anatomy and heart rate variability. Frontiers in Psychology. 2014;5:1040. https://doi.org/10.3389/fpsyg.2014.01040

[44] Meier M, Unternaehrer E, Dimitroff SJ, et al. In search of a standardized protocol for parasympathetic nervous system activation. PsyArXiv, 2020. https://doi.org/10.31234/osf.io/m85qC

[45] Löken LS. Wessberg J. Morrison I. McGlone F. Olausson H. Coding of pleasant touch by unmyelinated afferents in humans". Nature Neuroscience. 2009;12(5):547-548. https://doi.org/10.1038/nn.2312

[46] Gatti E, Calzolari E, Maggioni E, Obrist M. Emotional ratings and skin conductance response to visual, auditory and haptic stimuli. Sci Data. 2018; 5:180120. https://doi.org/10.1038/sdata.2018.120

[47] Nakano H, Kodama T, Ueda T, Mori I, Tani T, Murata, S. Effect of hand and foot massage therapy on psychological factors and EEG activity in elderly people requiring long-term care: A randomized cross-over study. Brain Sci. 2019; 9:54. https://doi.org/10.3390/brainsci9030054

[48] Gliga T, Farroni T, Cascio CJ. Social touch: A new vista for developmental cognitive neuroscience? Dev Cogn Neurosci. 2019;35:1-4. https://doi.org/10.1016/j.dcn.2018.05.006

[49] Inami T, Shimizu T, Baba R, Nakagaki A. Acute changes in autonomic nerve activity during passive static stretching. American J Sport Sci Med. 2014:2(4):166-170. https://doi.org/10.12691/ajssm-2-4-9 
[50] Wake E, Brack K. Characterization of the intrinsic cardiac nervous system. Auton Neurosci. 2016;199:3-16.

[51] Mooventhan A, Nivethitha L. Scientific evidence-based effects of hydrotherapy on various systems of the body. North Am J Med Sci. 2014:6(5):199-209. https://doi.org/10.4103/1947-2714.132935

[52] Carayannopoulos AG, Han A, Burdenko IN. The benefits of combining water and land-based therapy. J Exerc Rehabil. 2020;16(1):20-26. https://doi.org/10.12965/jer.1938742.371

[53] Doria O, Fricker E, Beery K. Effectiveness of alternative cerebral palsy treatments in pediatrics: Systematic review. Williams Honors College, Honors Research Projects. 896. 2019.

[54] Parker R, Higgins Z, Mlombile Z, Mohr MJ, Wagner TL. The effects of warm water immersion on blood pressure, heart rate and heart rate variability in people with chronic fatigue syndrome. South Afr J Physiotherapy. 2018;74(1):442. https://doi.org/10.4102/sajp.v74i1.442

[55] Becker BE. Hildenbrand K. Whitcomb RK, Sanders JP. Biophysiologic effects of warm water immersion. Int J Aquatic Res Educ. 2009;3(1):Article 4. https://doi.org/10.25035/ijare.03.01.04 